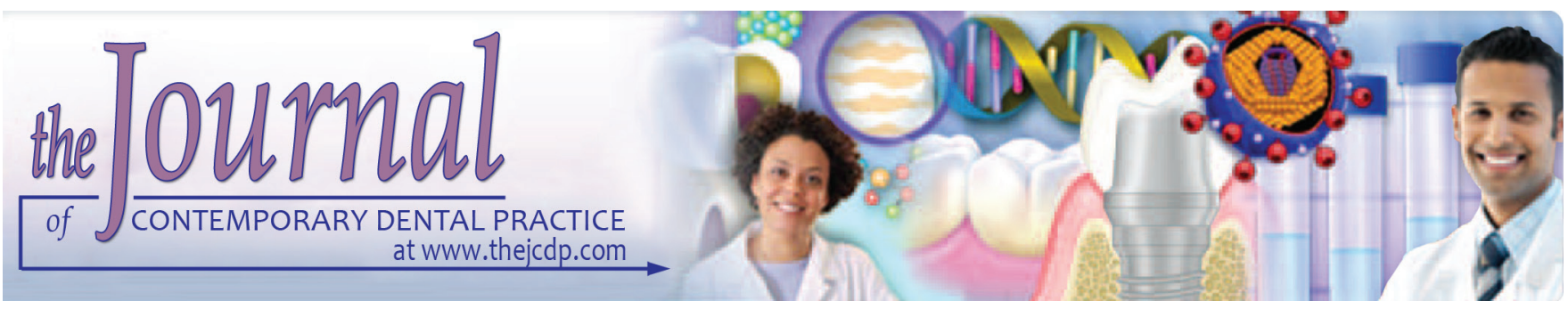

\title{
Comparison of Beta and ANB Angles for Evaluation of Sagittal Skeletal Discrepancy: A Cephalometric Study
}

\author{
${ }^{1}$ Atul Jajoo, ${ }^{2}$ Sanket S Agarkar, ${ }^{3}$ Shaivi Sharma, ${ }^{4}$ Nitin Gadhiya, ${ }^{5}$ Sushma Sonawane, ${ }^{6}$ Sameer Narkhede
}

\begin{abstract}
Aim: Diagnosis in orthodontic cases and treatment planning is a precise assessment of sagittal jaw relationship. A number of angular and linear measurements have been used to attain correct diagnosis. The present study is done to compare beta angle and A point-nasion-B point (ANB) angle for sagittal skeletal discrepancies.
\end{abstract}

\begin{abstract}
Materials and methods: A total of 105 subjects were included in between the age group of 18 and 24 years and were categorized based on the skeletal patterns as class I, class II, and class III having a sample of 35 in each group. Based on the ANB angle and patients' profile, the sample was divided into different skeletal groups. Beta angle is the angle amid the perpendicular from $C$ to $B$ line through point $A$ and the $A-B$ line. Analysis of variance (ANOVA) and post hoc Scheffe's test were applied to analyze dependent variables. The level of significance was set at p-value 0.05 .
\end{abstract}

Results: The mean scores of ANB for class I skeletal pattern were $2.46 \pm 0.460$, for class II, $5.64 \pm 1.258$, and for class III, $-1.03 \pm 1.618$. Similarly, significant differences were observed in beta angle for class I skeletal pattern as $31.71 \pm 3.885$, for class II, $24.97 \pm 2.162$, and for class III, $39.26 \pm 3.649$.

Conclusion: Both ANB and beta angle showed significant differences with different skeletal patterns.

Clinical significance: Both ANB and beta angle are awfully supportive diagnostic measurements to scrutinize sagittal jaw relationship.

Keywords: ANB angle, Beta angle, Skeletal discrepancy.

\footnotetext{
${ }^{1,3}$ Department of Orthodontics, Index Institute of Dental Science Indore, Madhya Pradesh, India

${ }^{2}$ Department of Orthodontics, Dr. D. Y. Patil Dental College \& Hospital, Dr. D. Y. Patil Vidyapeeth, Pune, Maharashtra, India

${ }^{4-6}$ Department of Orthodontics, D. Y. Patil University School of Dentistry, Navi Mumbai, Maharashtra, India

Corresponding Author: Atul Jajoo, Department of Orthodontics Index Institute of Dental Science, Indore, Madhya Pradesh, India e-mail: drnarkhede75@rediffmail.com
}

How to cite this article: Jajoo A, Agarkar SS, Sharma S, Gadhiya N, Sonawane S, Narkhede S. Comparison of Beta and ANB Angles for Evaluation of Sagittal Skeletal Discrepancy: A Cephalometric Study. J Contemp Dent Pract 2018;19(6):739-742.

Source of support: Nil

Conflict of interest: None

\section{INTRODUCTION}

The anteroposterior relation of maxilla to mandible is a significant diagnostic standard. It can be firmed from clinical examination to some degree, but precise assessment was not possible. Introduction of cephalometrics presented a leeway to assess sagittal relationship more perfectly. ${ }^{1}$ Traditionally, orthodontists have made maxilla and the mandible as the reference points for the cranial base of skull. $^{2}$

The appraisal of sagittal jaw relation among maxilla and mandible has been one of the chief hindrances in the branch of orthodontics. This is because of rotations of jaws during growth, vertical relationships between jaws and reference planes, and short of validity of the diverse techniques proposed for their assessment. ${ }^{3}$

Till now, many methods for assessing anteroposterior jaw base relationship have been developed. Previously, the skeletal pattern was used to measure by palpating the anterior basal part of jaw bone with teeth in centric occlusion position. After the introduction of the cephalometrics, different angular and linear parameters have been recorded to assess a variety of discrepancies. Downs in the year 1956 introduced the A-B plane angle; a few years later, Riedel came up with the angle ANB. ${ }^{4}$

Jacobson $^{5}$ introduced Wits appraisal as a substitute to ANB. It relates points A and B to the purposeful occlusal plane. The space between the points of intersection $\mathrm{AO}$ and $\mathrm{BO}$ is calculated to explain anteroposterior relationship.

Baik and Ververidou ${ }^{6}$ introduced the beta angle in 2004 to assess sagittal discrepancies. This method 
depends on points $\mathrm{A}$ and $\mathrm{B}$, which are hard to place, and point $C$ in condyle, which is not evidently noticeable either to overcome these problems. Beta angle makes use of three skeletal landmarks points A, B, and evident axis of the condyle-point $C{ }^{7}$ Hence, this study was planned to compare beta and ANB angle for the assessment of sagittal skeletal discrepancy.

\section{MATERIALS AND METHODS}

This investigation was done in the Department of Orthodontics for the assessment of sagittal skeletal discrepancies. A total of 105 subjects were included between 18 and 24 years of age.

Lateral cephalograms of study participants were taken prior to orthodontic treatment. The study sample comprised three skeletal pattern groups. Further, these three groups were categorized based on skeletal discrepancies as class I, class II, and class III having a sample of 35 in each group.

Based on ANB angle and patient's profile, the subjects were categorized into class I, class II, and class III skeletal group. The selection criteria to be included in class I skeletal pattern are: ANB angle of 2 to 3. Criteria for class II skeletal pattern: ANB angle of 4 to 8.5 and the criteria to be included in class III skeletal pattern is ANB angle of -5 to +1 . Beta angle is the angle lying perpendicular from $\mathrm{C}$ to $\mathrm{B}$ line through point $\mathrm{A}$ and the $\mathrm{A}-\mathrm{B}$ line.

Table 1: Description of landmarks

\begin{tabular}{|c|c|}
\hline Sella (S) & Middle point is the of hypophyseal fossa \\
\hline Nasion $(\mathrm{N})$ & $\begin{array}{l}\text { Anterior most landmark of the frontonasal } \\
\text { suture in the median plane }\end{array}$ \\
\hline $\begin{array}{l}\text { Anterior nasal } \\
\text { spine (ANS) }\end{array}$ & $\begin{array}{l}\text { Tip of the bone of anterior nasal spine, located } \\
\text { in the median plane }\end{array}$ \\
\hline Point A & $\begin{array}{l}\text { Innermost middle line landmark in the curved } \\
\text { bone drawn from the bottom to alveolar } \\
\text { process of maxilla }\end{array}$ \\
\hline Point B & $\begin{array}{l}\text { Posterior landmark in the external outline of } \\
\text { mandibular alveolar process, situated in the } \\
\text { median plane }\end{array}$ \\
\hline Gonion (Go) & $\begin{array}{l}\text { The junction of the lines' departure to } \\
\text { the posterior border of rising ramus and } \\
\text { mandibular base }\end{array}$ \\
\hline
\end{tabular}

Tracing of cephalometric was done by a solitary surveyor with the help of acetate tracing. The angles measured in this study group were ANB angle and beta angle (Tables 1 and 2).

The data were collected on excel sheet and analyzed by Statistical Package for the Social Sciences version 17.0 software. The ANOVA and post hoc Scheffe's test were applied to analyze dependent variables. Pearson's correlation was used to assess a possible linear association. The significance point was set at p-value 0.05 .

\section{RESULTS}

In this study, the mean scores of ANB for class I skeletal pattern were $2.46 \pm 0.460$, for class II, $5.64 \pm 1.258$ and for class III, $-1.03 \pm 1.618$. The differences in the scores were statistically significant. Similarly, significant differences were observed in beta angle for class I skeletal pattern as $31.71 \pm 3.885$, for class II, $24.97 \pm 2.162$ and for class III, $39.26 \pm 3.649$.

The results also depicted that the scores of ANB in class II skeletal pattern group were highest followed by class I and class III. In beta angle, the findings were more in class III group followed by class I and class II skeletal patterns as mentioned in Table 3.

The value of Pearson test between ANB angle and beta angle was -0.312 for class I pattern, -0.007 for class II, and -0.253 for class III skeletal pattern group. These differences of ANB and beta angle in relation to class I and class III skeletal pattern groups were not significant as shown in Table 4.

In Table 5, post hoc Scheffe's test compared the mean difference of the entire skeletal group patterns in ANB

Table 2: Cephalometric measurements

\begin{tabular}{|c|c|}
\hline S-N plane & Line joining the landmarks of Sella and Nasion \\
\hline SNA angle & $\begin{array}{l}\text { Angle formed by S-N plane and the line joining } \\
\text { the landmarks of } N \text { and point } A\end{array}$ \\
\hline SNB angle & $\begin{array}{l}\text { Angle generated by } \mathrm{S}-\mathrm{N} \text { plane and the line } \\
\text { joining landmarks of } N \text { and } B\end{array}$ \\
\hline ANB & Angle formed in between points $A, N$, and $B$ \\
\hline Beta angle & $\begin{array}{l}\text { Angle formed in between the last vertical line } \\
\text { from point } A \text { to } C-B \text { line and the } A-B \text { line }\end{array}$ \\
\hline
\end{tabular}

Table 3: Mean scores of ANB and beta angle in Class I, II, and III skeletal groups

\begin{tabular}{lllclll}
\hline & Skeletal pattern & No & Mean & SD & F value & $p$-value \\
\hline ANB & Class I & 35 & 2.46 & 0.460 & 265.102 & 0.000 \\
& Class II & 35 & 5.64 & 1.258 & 144.643 & 0.000 \\
& Class III & 35 & -1.03 & 1.618 & 385.561 & 0.000 \\
& Total & 105 & 2.36 & 2.989 & & \\
\multirow{5}{*}{ Beta angle } & Class I & 35 & 31.71 & 3.885 & 162.103 & 0.000 \\
& Class II & 35 & 24.97 & 2.162 & 90.289 & 0.000 \\
& Class III & 35 & 39.26 & 3.649 & 233.917 & 0.000 \\
\hline & Total & 105 & 31.98 & 6.722 & & \\
\hline
\end{tabular}


Table 4: Pearson correlation between ANB and beta angle in Class I, II, and III skeletal groups

\begin{tabular}{llll}
\hline Pearson correlation & ANB & Beta angle & $p$-value \\
\hline Class I & 1 & -0.312 & 0.068 \\
Class II & 1 & 0.007 & 0.968 \\
Class III & 1 & -0.253 & 0.143 \\
\hline
\end{tabular}

and beta angle and significant differences were found. The lowest and highest ranges were also mentioned.

\section{DISCUSSION}

Anteroposterior relationship between maxilla and mandible dental bases is known as skeletal pattern, sagittal apical base relationship, or jaw relationship. ${ }^{8}$ The literature revealed numerous ways to measure the skeletal pattern discrepancy, but none of the methods is universally accepted. Regardless of the fact that ANB angle is one of the commonly used cephalometric parameters for sagittal skeletal discrepancy, there are many articles mentioning that ANB angle is not consistent enough in skeletal class analysis. ${ }^{9,10}$ The current study used beta angle and ANB angle for assessing sagittal relationships and also to be acquainted with the reliability of beta angle.

The mean scores of ANB for class I skeletal pattern were $2.46 \pm 0.460$, for class II, $5.64 \pm 1.258$, and for class III, $-1.03 \pm 1.618$. The values for ANB angle were very close to the study by Richardson ${ }^{11}(2.32 \pm 1.92)$, Jarvinen ${ }^{12}(2.9 \pm$ 2.4). On the contrary, Riedel ${ }^{13}$ showed ANB mean values as 3.4 and Walker and Kowalski ${ }^{14}$ mentioned mean ANB values of 4.5 , which were high compared with the present findings. In population of Andhra Pradesh, ANB assessment for class I group can range from 0 to $4.5{ }^{1}$

Beta angle in this study showed mean scores for class I skeletal pattern as $31.71 \pm 3.885$, for class II, $24.97 \pm$ 2.162, and for class III, $39.26 \pm 3.649$. These statistics were similar to the previous studies ranging from the mean beta value of 27 to $37 .{ }^{15}$ An additional benefit of the beta angle is that it can be applied for successive comparisons all the way through orthodontic management because it shows accurate changes of the anteroposterior jaws relationship. ${ }^{10}$

In the present study, significant differences were observed in ANB and beta angle for all the three skeletal groups as class I, class II, and class III. These figures were comparable to the results of study done by Agarwal et al ${ }^{16}$ in Jaipur populace. Baik and Ververidou ${ }^{6}$ also mentioned that beta angle numbers were significant $(p<0.001)$ among all the three skeletal groups. The authors also stated that beta angle does not depend on functional occlusal plane or cranial landmarks and stays comparatively steady even when the jaws are rotated.

Relwani et $\mathrm{al}^{10}$ showed significant correlation and maximum correlation was found between $\mathrm{FH}$ to $\mathrm{AB}$ plane angle (FABA) and beta angle followed by FABA and palatal plane to AB plane angle (PABA), YEN and beta. However, least possible correlation was found between PABA and YEN.

In the same way, Sachdeva et $\mathrm{al}^{9}$ in their cephalometric study assessed the sagittal relationship between maxilla and mandible and compared Wits appraisal, ANB angle, beta angle, and $\mathrm{W}$ angle, for consistent measurement. They also mentioned that YEN angle, beta angle, and $\mathrm{W}$ angle are noteworthy angles to calculate sagittal jaw relationship between maxilla and mandible.

The present findings observed that ANB values in class II skeletal pattern group were highest followed by class I and class III. Whereas in beta angle, class III group were at peak followed by class I and class II skeletal patterns. These results were comparable to the study conducted by Agarwal et $\mathrm{al}^{16}$ in Jaipur population.

Moreover, a positive correlation was noticed of ANB angle with beta angle in relation to class I and class III skeletal pattern groups. Correspondingly, Maruthi and Kandasamy ${ }^{17}$ stated a significant difference in the mean scores of beta angle for class I, class II, and class III skeletal pattern groups of Chennai population.

Table 5: Mean difference of ANB and beta angle in skeletal patterns Class I, II, and III using post hoc Scheffe test

\begin{tabular}{|c|c|c|c|c|c|c|}
\hline \multirow{2}{*}{$\begin{array}{l}\text { Dependent variable } \\
\text { ANB }\end{array}$} & \multirow{2}{*}{$\begin{array}{l}\text { Class I } \\
\text { Cla }\end{array}$} & \multirow{2}{*}{$\begin{array}{l}(\mathrm{J}) \\
\text { Class II }\end{array}$} & \multirow{2}{*}{$\begin{array}{l}\text { Mean difference }(I-J) \\
-3.186\end{array}$} & \multirow{2}{*}{$\begin{array}{l}p \text {-value } \\
0.000\end{array}$} & \multicolumn{2}{|c|}{$95 \%$ confidence interval } \\
\hline & & & & & -3.91 & -2.47 \\
\hline & & Class III & 3.486 & 0.000 & 2.77 & 4.21 \\
\hline & Class II & Class I & 3.186 & 0.000 & 2.47 & 3.91 \\
\hline & & Class III & 6.671 & 0.000 & 5.95 & 7.39 \\
\hline & Class III & Class I & -3.486 & 0.000 & -4.21 & -2.77 \\
\hline & & Class II & -6.671 & 0.000 & -7.39 & -5.95 \\
\hline \multirow[t]{6}{*}{ Beta angle } & Class I & Class II & 6.743 & 0.000 & 4.77 & 8.71 \\
\hline & & Class III & -7.543 & 0.000 & -9.51 & -5.57 \\
\hline & Class II & Class I & -6.743 & 0.000 & -8.71 & -4.77 \\
\hline & & Class III & -14.286 & 0.000 & -16.26 & -12.31 \\
\hline & Class III & Class I & 7.543 & 0.000 & 5.57 & 9.51 \\
\hline & & Class II & 14.286 & 0.000 & 12.31 & 16.26 \\
\hline
\end{tabular}




\section{CONCLUSION}

The study revealed that ANB and beta angle act as a valuable tool for assessing the different skeletal patterns. These findings can be implemented for orthodontic diagnosis and treatment planning adding up to the conventionally used dimensions.

\section{REFERENCES}

1. Polina VS, Prakash AS, Paturi S, Mummidi B, Varma PK, Kumar BS. Establishment of cephalometric norms for four sagittal skeletal discrepancy indicators in Andhra population. J NTR Univ Health Sci 2015 Sep;4(3):165-169.

2. Downs WB. Variations in facial relationships: their significance in treatment and prognosis. Am J Orthod 1948 Oct;34(10):812-840.

3. Bhad WA, Nayak S, Doshi UH. A new approach of assessing sagittal dysplasia: the W angle. Eur J Orthod 2013 Feb; 35(1):66-70.

4. Doshi JR, Trivedi K, Shyagali T. Predictability of yen angle \& appraisal of various cephalometric parameters in the assessment of sagittal relationship between maxilla and mandible in Angle's class II malocclusion. People J Sci Res 2012 Jan;5(1):1-8.

5. Jacobson A. The "Wits" appraisal of jaw disharmony. Am J Orthod 1975 Feb;67(2):125-138.

6. Baik CY, Ververidou M. A new approach of assessing sagittal discrepancies: the Beta angle. Am J Orthod Dentofacial Orthop 2004 Jul;126(1):100-105.

7. Bhardwaj P, Kapoor DN, Rani MS. Assessment of sagittal skeletal discrepancy: a cephalometric study. J Ind Orthod Soc 2013 Oct-Dec;47(4):262-265.
8. Aparna P, Kumar DN, Prasad M, Shamnur N, Kumar A, Shridhar KR, Gupta N, BR GK. Comparative assessment of sagittal skeletal discrepancy: a cephalometric study. J Clin Diagn Res 2015 Apr;9(4):38-41.

9. Sachdeva K, Singla A, Mahajan V, Jaj HS, Seth V, Nanda M. Comparison of different angular measurements to assess sagittal skeletal discrepancy-a cephalometric study. Indian J Dent Sci 2012;2(4):27-29.

10. Relwani P, Gowda NC, Ramegowda S. Comparative assessment of changes in sagittal relationship of maxilla to mandible in class II malocclusion-a cephalometric study. Indian J Orthod Dentofac Res 2016 Apr-Jun;2(2):77-82.

11. Richardson M. Measurement of dental base relationship. Eur J Orthod 1982 Nov;4(4):251-256.

12. Jarvinen S. A comparison of two angular and two linear measurements used to establish sagittal apical base relationship. Eur J Orthod 1981 Jan;3(2):131-134.

13. Riedel RA. The relation of maxillary structures cranium in malocclusion and in normal occlusion. Angle Orthod 1952;22:142-145.

14. Walker GF, Kowalski CJ. The distribution of the ANB angle in "normal" individuals. Angle Orthod 1971 Oct;41(4):332-335.

15. Bhatia SN, Akpabio TA. A correlation study of two methods of assessing skeletal pattern. Br J Orthod 1979;6:187-193.

16. Agarwal R, Sharma L, Soni VK. Comparison of different angular measurements to assess sagittal jaw discrepancy in Jaipur population—a cephalometric study. J Dent Med Sci 2013 Jan;10(1):33-36.

17. Maruthi V, Kandasamy S. Establishment of norms of the beta angle to assess the sagittal discrepancy for Chennai population: a prospective study. Int J Pedod Rehabil 2016 Dec;1(2):52-55. 